\title{
Comparison of Viscoelastic Substance Injection Versus Air Filling in the Anterior Chamber During Foldable Capsular Vitreous Body (FCVB) Implant Surgery: A Prospective Randomized Controlled Trial
}

\author{
Zhongyu Zhang $\cdot$ Shujie Liu $\cdot$ Fang Xie $\cdot$ Bo Jiang $\cdot$ Meng Sun · \\ Dawei Sun
}

Received: March 29, 2021 / Accepted: June 22, 2021 / Published online: August 5, 2021

(C) The Author(s) 2021

\section{ABSTRACT}

Introduction: To compare the outcomes of viscoelastic substance injection with air filling in the anterior chamber during foldable capsular vitreous body (FCVB) implant surgery in patients with severe retinal disease.

Methods: Thirty eyes with severe retinal diseases were randomly divided into two groups.

Supplementary Information The online version contains supplementary material available at https:// doi.org/10.1007/s12325-021-01840-5.

\section{Z. Zhang $\cdot$ B. Jiang $\cdot$ D. Sun $(\bowtie)$}

Department of Ophthalmology, The Second Affiliated Hospital of Harbin Medical University, No.246 Xuefu Road, Harbin 150086, China e-mail: sun.dawei@hotmail.com

S. Liu

Department of Anesthesiology, The First Affiliated Hospital of Harbin Medical University, Harbin 150001, China

F. Xie

Department of Ophthalmology, The First Affiliated Hospital of Harbin Medical University, Harbin 150001, China

\section{Sun}

Department of Cardiology, The Second Affiliated Hospital of Harbin Medical University, Harbin 150086, China

\section{Sun}

The Key Laboratory of Myocardial Ischemia, Chinese Ministry of Education, Harbin 150081, China
In the viscoelastic group, $0.15-0.2 \mathrm{~mL}$ of $1.7 \%$ sodium hyaluronate was injected into the anterior chamber after FCVB implantation; in the air group, the anterior chamber was maintained by filling the air after FCVB implant surgery. The eyes of treated patients were examined during a 24-week follow-up appointment. Data, including intraocular pressure (IOP), the difference between preoperative and postoperative IOP, and postoperative complications, were recorded.

Results: Data collected from 27 eyes were used in the final analysis. The IOP of the air group was lower than that of the viscoelastic group from the first to third postoperative day $(P<0.01)$. Moreover, the difference between preoperative and postoperative IOP in the viscoelastic group was significantly smaller than that in the air group from the first to third postoperative day $(P<0.01)$. After the 1 st postoperative week, postoperative IOP values were similar in the two groups $(P>0.05)$. Postoperative complications in the air group and the viscoelastic group included corneal blood staining (1 eye vs. 0 eyes), transient postoperative diffuse hemorrhage (5 eyes vs. 1 eye), inflammation reaction ( 9 eyes vs. 4 eyes), and postoperative fibrin exudation (4 eyes vs. 1 eye), respectively.

Conclusion: The use of viscoelastic substances in the anterior chamber during FCVB implant surgery was associated with less fluctuation in 
postoperative IOP and could reduce postoperative complications.

Registration Number: ChiCTR-TNC-00000396.

Keywords: Anterior chamber; FCVB; IOP; Retinal diseases; Viscoelastic

$\begin{array}{ll}\text { Abbreviations } \\ \text { CB } & \text { Ciliary body } \\ \text { FCVB } & \text { Foldable capsular vitreous body } \\ \text { IOP } & \text { Intraocular pressure } \\ \text { PVR } & \text { Proliferative vitreoretinopathy } \\ \text { PPV } & \text { Pars plana vitrectomy } \\ \text { SO } & \text { Silicone oil }\end{array}$

\section{Key Summary Points}

Why carry out this study?

Some complications of foldable capsular vitreous body (FCVB) implant surgeries have been associated with intraocular pressure (IOP) reduction. In this study, we hypothesized that sodium hyaluronate, a kind of naturally occurring viscoelastic, could relieve postoperative IOP reduction when applied after FCVB implantation.

\section{What was learned from the study?}

Injection of viscoelastic substance in the anterior chamber during surgery could relieve postoperative IOP reduction. During a 24-week follow-up, a smaller fluctuation of postoperative IOP and fewer complications were found in patients who received viscoelastic treatment in the anterior chamber during surgery. Clinical ophthalmologists should consider regularly applying viscoelastic substances for FCVB implantation.

\section{DIGITAL FEATURES}

This article is published with digital features, including video slides, to facilitate understanding of the article. To view digital features for this article go to https://doi.org/10. 6084/m9.figshare.14823105.

\section{INTRODUCTION}

The vitreous body is a transparent gelatinoid structure that occupies four-fifths of the volume in the eye [1]. The vitreous substitute is necessary to tamponade the reattached retina after vitrectomy for severely damaged eyes [2]. Foldable capsular vitreous body (FCVB), which was developed in China, is a novel device used to replace natural vitreous [3-5]. It has excellent mechanical strength, refractivity, and biocompatibility [6]. FCVB can prevent silicon oil displacement and emulsification. Unlike silicon oil and air tamponade, there is no more need for patients to keep prone positions after surgery [7]. In some clinical trials, FCVB was applied to treat severe retinal diseases, showing good stability and efficacy after vitrectomy [6-8]. Moreover, FCVB implant surgeries have been associated with intraocular pressure (IOP) reduction and fewer complications.

After air-fluid exchange, the FCVB is implanted into the vitreous cavity, after which the air, balanced salt solution, or viscoelastic substances are used to maintain the anterior chamber. However, the air harms corneal endothelial cells in a time-dependent manner $[9,10]$. Moreover, balanced salt solution has low viscosity and a short residence time in the anterior chamber and will probably be replaced by aqueous humor. Viscoelastic substances are indispensable materials for intraocular surgery $[11,12]$. Sodium hyaluronate $(\mathrm{Na}-\mathrm{HA})$ is a kind of naturally occurring viscoelastic. It is a high molecular mass polysaccharide present in the extracellular matrix of connective tissues. It is also found in the aqueous humor and the vitreous and coats of the corneal endothelium [13]. Nevertheless, it remains unclear whether Na-HA could effectively maintain IOP and reduce postoperative complications.

The aim of this study was to compare Na-HA injected into the anterior chamber with regularly applied air after FCVB implantation by 
testing the change in IOP and postoperative complications.

\section{METHODS}

\section{Trial Design}

In this prospective randomized controlled trial, two surgical procedures (air or viscoelastic substance in the anterior chamber after FCVB implantation) were compared in two independent samples (parallel-group design). This trial was performed in the Department of Ophthalmology, the Second Affiliated Hospital of Harbin Medical University. The study was approved by the institutional review board (IRB), the Human Research Ethics Committee of the Second Affiliated Hospital of Harbin Medical University (Registration number ChiCTR-TNC00000396). Written informed consent was obtained from each patient before enrollment in the trial.

\section{Participants}

Thirty eyes requiring FCVB implant to treat severe retinal detachment were enrolled between January 1, 2014 and December 31, 2018. Patients were randomly divided into the viscoelastic group or the air group based on a blocked randomization scheme (block size $=$ 30). Participants showed no other ophthalmological or severe systemic diseases. Excluded criteria were patients with serious heart, lung, liver, or kidney dysfunction; serious eye inflammation; only one eye affected; suitably silicone oil-filled eyes; or diseases that made them unsuitable for inclusion. The inclusion and exclusion criteria are outlined in Table 1.

All the patients agreed to be examined eight times after surgery: the 1st, 2nd, and 3rd day, the 1st, 2nd, 4th, 12th, and 24th week after surgery. Additional examinations were performed in the case of reoperations or at any unscheduled visit (e.g., because of concomitant therapy or adverse events).
Table 1 Inclusion and exclusion criteria

\begin{tabular}{|c|c|}
\hline Inclusion criteria & Exclusion criteria \\
\hline Able to attend follow-up & Only one eye \\
\hline $\begin{array}{l}\text { The treated eyes should } \\
\text { below PVR-B }\end{array}$ & Serious eye inflammation \\
\hline Axial length $\leq 28 \mathrm{~mm}$ & $\begin{array}{l}\text { Suitably silicone oil-filled } \\
\text { eyes }\end{array}$ \\
\hline $\begin{array}{l}\text { A severe retinal detachment } \\
\text { (could not be cured with } \\
\text { SO tamponade; rigid } \\
\text { retinal re-detachments or } \\
\text { inferior holes that } \\
\text { occurred after more than } \\
3 \text { months of SO } \\
\text { tamponade) }\end{array}$ & $\begin{array}{l}\text { Glaucoma (NVG; } \\
\text { traumatic glaucoma; } \\
\text { persistent ocular } \\
\text { hypertension) }\end{array}$ \\
\hline $\begin{array}{l}\text { Severe posterior trauma } \\
\text { (posterior scleral ruptures } \\
\text { with large disruptions of } \\
\text { the retina; severe scleral } \\
\text { ruptures with retinal } \\
\text { detachments and } \\
\text { choroidal damage) }\end{array}$ & $\begin{array}{l}\text { Unoperated eye (uveitis; } \\
\text { sympathetic ophthalmia) }\end{array}$ \\
\hline \multirow[t]{2}{*}{$\begin{array}{l}\text { Predislocated vision: HM, } \\
\text { LP, and NLP }\end{array}$} & Scar physique \\
\hline & $\begin{array}{l}\text { Serious heart, lung, liver, or } \\
\text { kidney dysfunction }\end{array}$ \\
\hline
\end{tabular}

$S O$ silicone oil, $H M$ hand movements, $L P$ light perception, $N L P$ no light perception, $N V G$ neovascular glaucoma, $P V R$ proliferative vitreoretinopathy

\section{Surgery}

In both groups, standard 23-gauge 3-port pars plana vitrectomy (PPV) was used to remove the vitreous. If eyes were filled with $\mathrm{SO}, \mathrm{SO}$ was first removed. The peeling of retinopathy proliferative membrane, relaxing peripheral retinotomy, and removal of the subretinal membrane were then performed to reattach severe retinal detachments. After air-fluid exchange, an incision of about $3.5 \mathrm{~mm}$ was made on the sclera of the FCVB implantation site at either the 4 or 
8 o'clock position, $4 \mathrm{~mm}$ away from the corneal limbus (Fig. 1). The FCVB was triple folded and implanted into the vitreous cavity. SO was then injected into the capsule to fill the FCVB (Fig. 1). The valve was fixed on the sclera. In the viscoelastic group, $1.7 \%$ Na-HA (Bausch \& Lomb Co., Ltd., Shang Dong, China) 0.15$0.2 \mathrm{~mL}$ was injected into the anterior chamber (see Video 1); in the air group, the anterior chamber was maintained by air after FCVB implantation (see Video 2). Then conjunctival and sclera incisions were sewed by interrupted sutures in both groups.

\section{Data Collection}

All patients were assessed at eight scheduled follow-up visits. The primary outcomes were IOP and the difference between preoperative and postoperative IOP. The IOP was tested by two senior doctors using Goldmann applanation measurement technique with a slit lamp.
The average value of the two results was the final IOP value. Secondary outcomes were vitreous hemorrhage, hyphema, and corneal blood staining after surgery. IOP was measured at every visit. The anterior segment was explored and recorded for signs of inflammation and hyphema using a slit lamp. Retinal reattachments were analyzed by B-scans. CT and MRI were used to evaluate retinal reattachments when B-scans failed to provide definite data on retinal reattachments.

\section{Statistical Analysis}

A sample size calculation was performed and based on the assumption that the study was only concerned with a change in IOP caused by the operation. A sample size of 13 patients in each group could provide $80 \%$ power at a twosided alpha level of 0.05 to detect a difference of $3.0 \mathrm{mmHg}$ at a standard deviation of $2.5 \mathrm{mmHg}$.

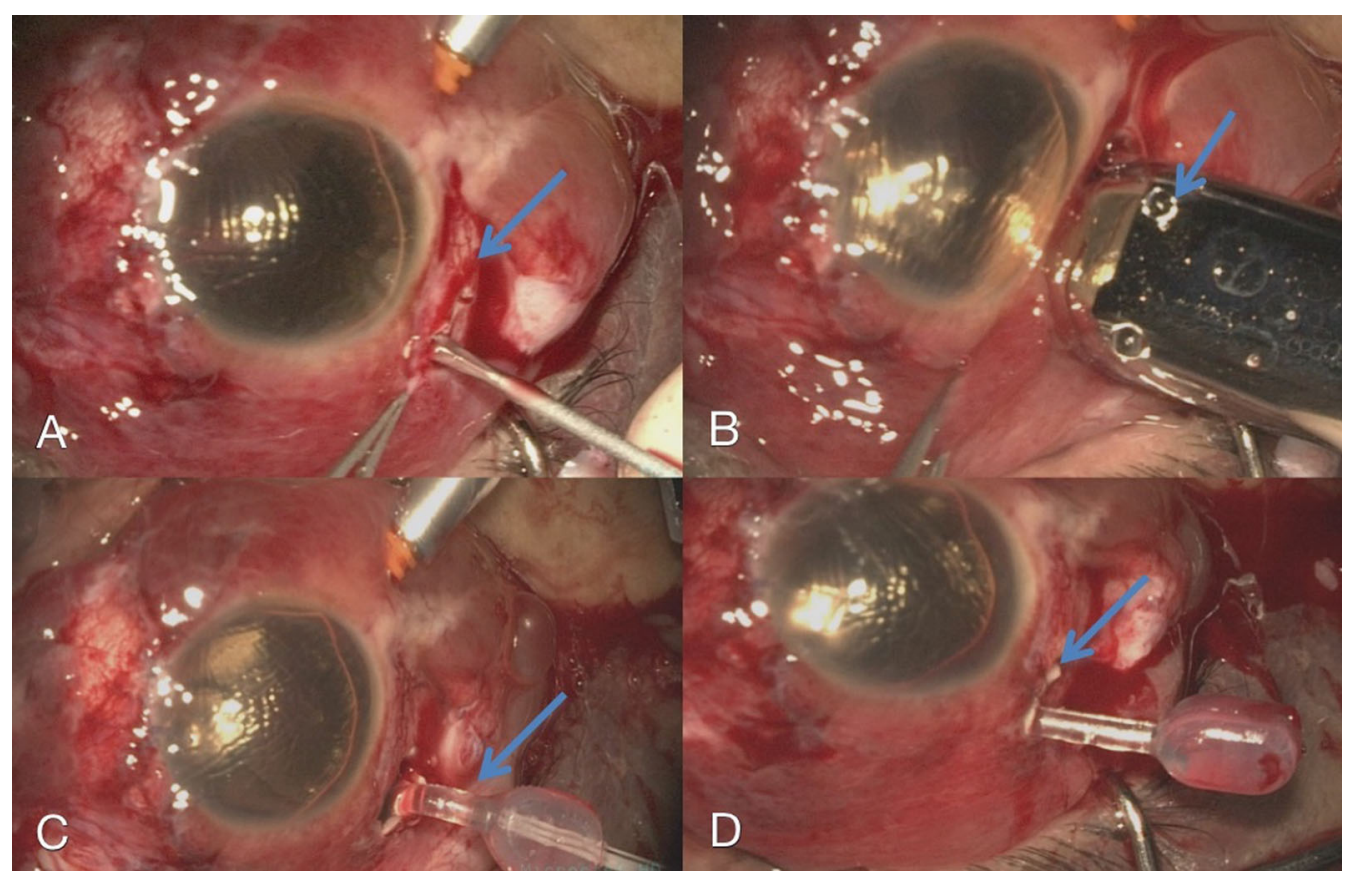

Fig. 1 Procedure of foldable capsular vitreous body (FCVB) implantation. A A scleral incision of about $3.5 \mathrm{~mm}$ was created by a 20G MVR blade in the superiortemporal quadrant. B The FCVB was triple folded and implanted into the vitreous cavity through the scleral incision. C Silicone oil was injected into the capsule to fill the FCVB through the valve. $\mathbf{D}$ The sclera incision was closed by interrupted sutures 
Table 2 Patients characteristics of the two groups

\begin{tabular}{|c|c|c|c|}
\hline & $\begin{array}{l}\text { Air group } \\
(n=13)\end{array}$ & $\begin{array}{l}\text { Viscoelastic } \\
\text { group } \\
(n=14)\end{array}$ & $P$ value \\
\hline Male, $n(\%)$ & $10(76.9)$ & $11(78.6)$ & 1.0000 \\
\hline Age, mean $\pm S D$ & $41.8 \pm 13.5$ & $42.4 \pm 14.2$ & 0.9134 \\
\hline Right eye, $n$ (\%) & $7(53.8)$ & $6(42.9)$ & 0.7064 \\
\hline Aphakic, $n(\%)$ & $8(61.5 \%)$ & $10(71.4)$ & 0.7445 \\
\hline Phakic, $n(\%)$ & $4(30.8)$ & $3(21.4)$ & 0.8303 \\
\hline $\begin{array}{l}\text { Pseudophakic, } \\
\quad n(\%)\end{array}$ & $1(7.7)$ & $1(7.1)$ & 1.0000 \\
\hline $\begin{array}{l}\text { Severe posterior } \\
\text { trauma: large } \\
\text { disruptions of } \\
\text { the retina, } n(\%)\end{array}$ & $5(38.5)$ & $6(42.9)$ & 1.0000 \\
\hline $\begin{array}{l}\text { Severe scleral } \\
\text { ruptures: retinal } \\
\text { and choroidal } \\
\text { detachments, } \\
n(\%)\end{array}$ & $3(23.1)$ & $2(14.3)$ & 0.6483 \\
\hline $\begin{array}{l}\text { Severe PVR: } \\
\text { retinal } \\
\text { detachments } \\
\text { after two or } \\
\text { more silicone oil } \\
\text { tamponade, } \\
n(\%)\end{array}$ & $2(15.4)$ & $3(21.4)$ & 1.0000 \\
\hline $\begin{array}{l}\text { Severe retinal } \\
\text { detachment: } \\
\text { failed to } \\
\text { respond to } \\
\text { silicone oil, } \\
n(\%)\end{array}$ & $2(15.4)$ & $2(14.3)$ & 1.0000 \\
\hline $\begin{array}{l}\text { Severe PVR: failed } \\
\text { to respond to } \\
\text { heavy silicone } \\
\text { oil, } n(\%)\end{array}$ & $1(7.7)$ & $1(7.1)$ & 1.0000 \\
\hline
\end{tabular}

Data are presented as number (proportion) or mean $\pm \mathrm{SD}$ PVR proliferative vitreoretinopathy
Table 3 Intraoperative data of the two groups

\begin{tabular}{|c|c|c|c|}
\hline & $\begin{array}{l}\text { Air group } \\
(n=13)\end{array}$ & $\begin{array}{l}\text { Viscoelastic } \\
\text { group } \\
(n=14)\end{array}$ & $P$ value \\
\hline $\begin{array}{l}\text { Length of } \\
\text { procedure, } \\
\text { min }\end{array}$ & $106.8 \pm 8.5$ & $110.54 \pm 9.6$ & 0.2919 \\
\hline $\begin{array}{l}\text { Vitrectomy, } \\
n(\%)\end{array}$ & $11(84.6)$ & $12(85.71)$ & 1.0000 \\
\hline $\begin{array}{l}\text { Lensectomy, } \\
n(\%)\end{array}$ & $4(30.8)$ & $3(21.4)$ & 0.6776 \\
\hline $\begin{array}{l}\text { IOL removal, } \\
n(\%)\end{array}$ & $1(7.7)$ & $1(7.1)$ & 1.0000 \\
\hline $\begin{array}{l}\text { Scleral buckle, } \\
\text { n(\%) }\end{array}$ & $0(0)$ & $0(0)$ & - \\
\hline Cryopexy, $n(\%)$ & $0(0)$ & $0(0)$ & - \\
\hline $\begin{array}{l}\text { Removal of } \\
\text { silicone oil, } \\
n(\%)\end{array}$ & $3(23.1)$ & $3(21.4)$ & 1.0000 \\
\hline Laser, $n(\%)$ & $13(100)$ & $14(100)$ & - \\
\hline $\begin{array}{l}\text { Iridectomy at } 6 \\
\text { o'clock, } n(\%)\end{array}$ & $13(100)$ & $14(100)$ & - \\
\hline $\begin{array}{l}\text { Peripheral } 360^{\circ} \\
\text { retinotomy, } \\
n(\%)\end{array}$ & $8(61.5)$ & $9(64.3)$ & 1.0000 \\
\hline $\begin{array}{l}\text { Radial } \\
\text { retinotomy, } \\
n(\%)\end{array}$ & $1(7.7)$ & $1(7.1)$ & 1.0000 \\
\hline
\end{tabular}

Data are presented as number (proportion) or mean $\pm \mathrm{SD}$

The data between groups were compared using the Student $t$ test, the Fisher exact test, or the profile analysis with unstructured covariance taking into consideration the correlation of repeated readings from the same individuals. A two-sided $P$ value of less than 0.05 was considered to be statistically significant. SAS 9.2 (SAS Institute, Cary, NC, USA) software package was used. 
Table 4 IOP values and the difference between preoperative and postoperative IOP values at different time points

\begin{tabular}{|c|c|c|c|c|c|c|}
\hline \multirow[t]{2}{*}{ Time points } & \multicolumn{2}{|c|}{ Air group $(n=13)$} & \multicolumn{2}{|c|}{ Viscoelastic group $(n=14)$} & \multirow{2}{*}{$P_{1}$ value } & \multirow{2}{*}{$\begin{array}{l}P_{2} \\
\text { value }\end{array}$} \\
\hline & $\begin{array}{l}\text { IOP value } \\
(\mathrm{mmHg})\end{array}$ & $\begin{array}{l}D \text { value } \\
(\mathbf{m m H g})\end{array}$ & $\begin{array}{l}\text { IOP value } \\
(\mathrm{mmHg})\end{array}$ & $\begin{array}{l}D \text { value } \\
(\mathbf{m m H g})\end{array}$ & & \\
\hline Preoperative baseline & $12.90 \pm 2.61$ & & $12.55 \pm 3.20$ & & 0.759 & \\
\hline Postoperative 1st day & $8.84 \pm 2.38$ & $4.06 \pm 4.02$ & $14.16 \pm 2.40$ & $-1.61 \pm 1.53$ & $<0.0001$ & 0.0002 \\
\hline $\begin{array}{l}\text { Postoperative 2nd } \\
\text { day }\end{array}$ & $9.89 \pm 2.17$ & $3.01 \pm 3.55$ & $13.42 \pm 2.13$ & $-0.87 \pm 1.45$ & $<0.0001$ & 0.0022 \\
\hline Postoperative 3rd day & $11.15 \pm 1.51$ & $1.75 \pm 2.92$ & $13.88 \pm 1.62$ & $-1.33 \pm 2.39$ & 0.0014 & 0.0060 \\
\hline $\begin{array}{l}\text { Postoperative 1st } \\
\text { week }\end{array}$ & $12.32 \pm 1.68$ & $0.58 \pm 2.06$ & $13.52 \pm 0.92$ & $-0.97 \pm 2.57$ & 0.1522 & 0.0962 \\
\hline $\begin{array}{l}\text { Postoperative 2nd } \\
\text { week }\end{array}$ & $12.55 \pm 1.99$ & $0.35 \pm 3.29$ & $13.56 \pm 2.53$ & $-1.01 \pm 2.93$ & 0.2299 & 0.2662 \\
\hline $\begin{array}{l}\text { Postoperative 4th } \\
\text { week }\end{array}$ & $11.82 \pm 1.36$ & $1.08 \pm 3.33$ & $11.99 \pm 1.80$ & $0.56 \pm 2.28$ & 0.8140 & 0.6328 \\
\hline $\begin{array}{l}\text { Postoperative 12th } \\
\text { week }\end{array}$ & $11.60 \pm 1.19$ & $1.30 \pm 1.93$ & $11.89 \pm 1.59$ & $0.66 \pm 2.48$ & 0.6979 & 0.4613 \\
\hline $\begin{array}{l}\text { Postoperative 24th } \\
\text { week }\end{array}$ & $11.02 \pm 1.27$ & $1.88 \pm 2.17$ & $11.13 \pm 1.59$ & $1.42 \pm 2.19$ & 0.8807 & 0.5865 \\
\hline
\end{tabular}

$I O P$ intraocular pressure, $D$ difference of IOP values $=$ IOP value at preoperative baseline - IOP values at the postoperative time point, $P_{1}$ for IOP value comparison between groups, $P_{2}$ for $D$ value comparison between groups

\section{RESULTS}

One patient from the air group refused to participate in the study before the beginning of surgery. Two additional patients, one from the air group and one from the viscoelastic group, were lost to follow-up. Three patients were excluded from this study. Finally, 27 eyes were included in the analysis.

Table 2 summarizes the demographic and baseline characteristics of patients in this study. There were no significant differences between the two groups concerning the demographic profile and the baseline characteristics $(P>0.05)$. Intraoperative data are summarized in Table 3 . The procedure lasted $106.8 \pm 8.5 \mathrm{~min}$ in the air group and $110.5 \pm 9.6 \mathrm{~min}$ in the viscoelastic group; no significant difference was observed between the two groups $(P=0.2919)$. There was no significant difference between the two groups in the reattachment rate of severe retinal detachments $(P=1.0000)$. No leakage of the FCVB was found, and nor was FCVB removed from the eyes.

There was no significant difference between groups in baseline IOP (Table 4). On the 1st day after the operation, IOP in the viscoelastic group was $14.16 \pm 2.40 \mathrm{mmHg}$, which was significantly higher than that in the air group $(8.84 \pm 2.38 \mathrm{mmHg}) \quad(P<0.0001)$. The same phenomenon was observed on the 3rd day after the operation with $13.88 \pm 1.62 \mathrm{mmHg}$ in the viscoelastic group versus $11.15 \pm 1.51 \mathrm{mmHg}$ in the air group $(P=0.0014)$. The difference between groups began to narrow and was no longer significant from the 1st week after operation $(P>0.05)$ (Fig. 2).

Postoperative IOP in both groups varied at different time points (Table 4). On the 1st day after the operation, postoperative IOP increased by $1.61 \pm 1.53 \mathrm{mmHg}$ in the viscoelastic group while it decreased by $4.06 \pm 4.02 \mathrm{mmHg}$ in the 


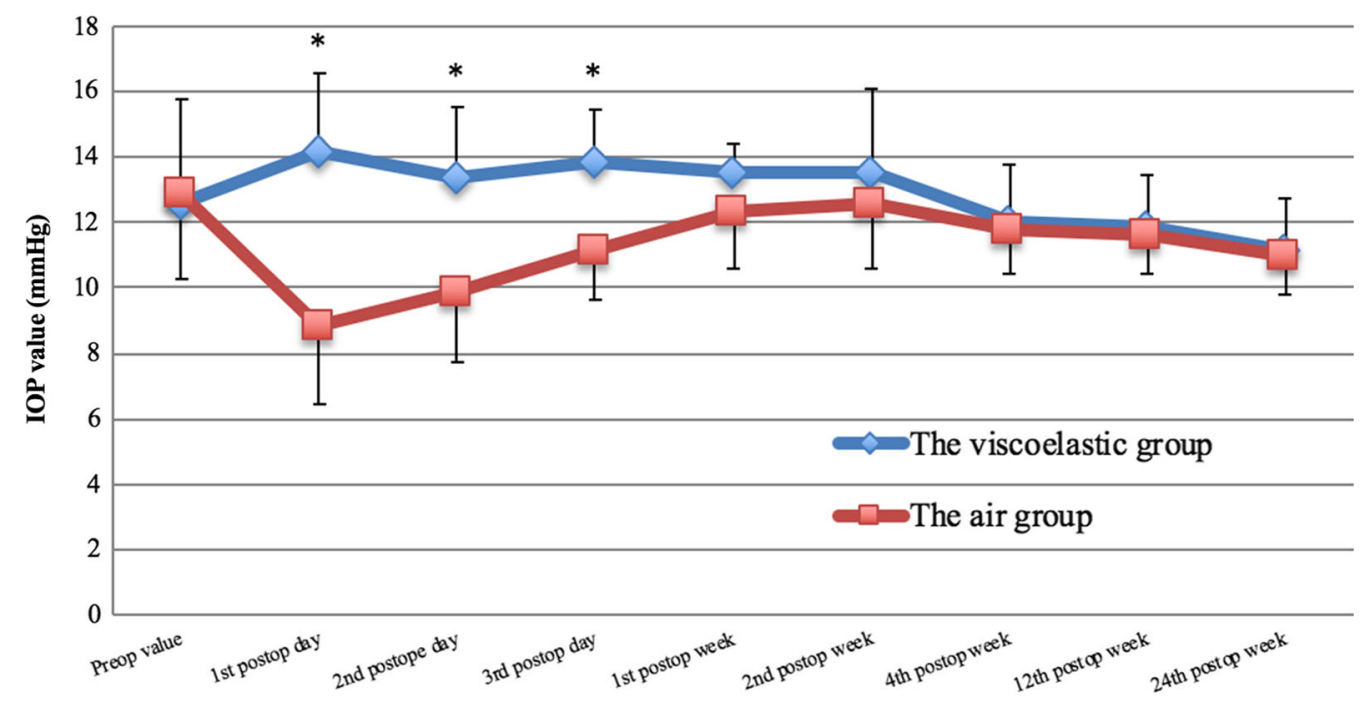

Different time points

Fig. 2 Postoperative IOP change in the two groups. ${ }^{*} P<0.01$ for comparison between groups

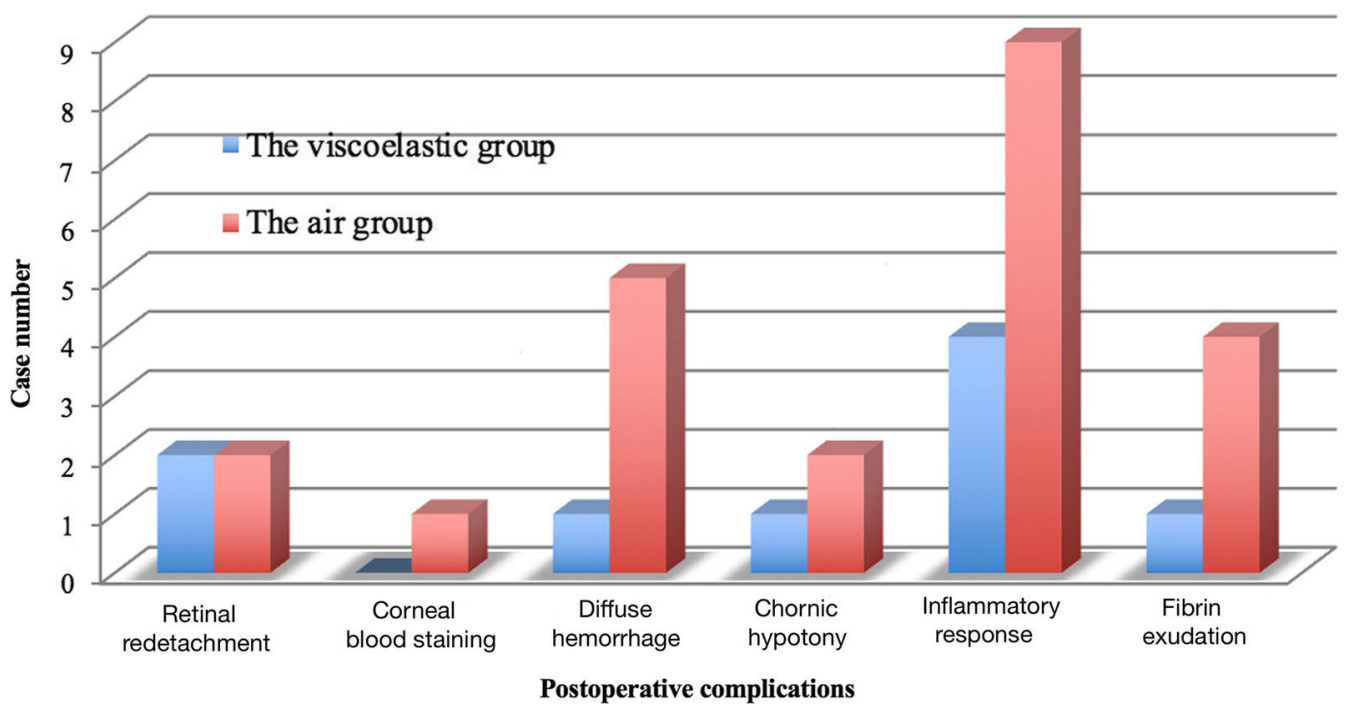

Fig. 3 Postoperative complications in two groups of patients. Diffuse hemorrhage: diffuse hemorrhage in the anterior chamber and the vitreous cavity. In the air group, diffuse hemorrhage in the anterior chamber and the vitreous cavity were seen in 5 eyes; in the viscoelastic group, transient postoperative diffuse hemorrhage in the vitreous cavity was absorbed in 1 eye only. The postoperative inflammatory response included inflammatory cells,

air group compared with preoperative IOP value $(P=0.0002)$. Similarly, postoperative IOP increased by $1.33 \pm 2.39 \mathrm{mmHg}$ in the fibrin, and flare in the anterior chamber, which are displayed in this figure respectively. In the air group, the postoperative inflammatory response was seen in 6 eyes. Among 6 eyes with inflammatory cells in the anterior chamber, 2 eyes were swollen up and 1 eye was with fibrin in the anterior chamber. In the viscoelastic group, inflammatory cells in the anterior chamber were found in only 2 eyes

viscoelastic group and decreased by $1.75 \pm 2.92 \mathrm{mmHg}$ in the air group on the 3rd day after surgery $(P=0.0060)$. Compared with 


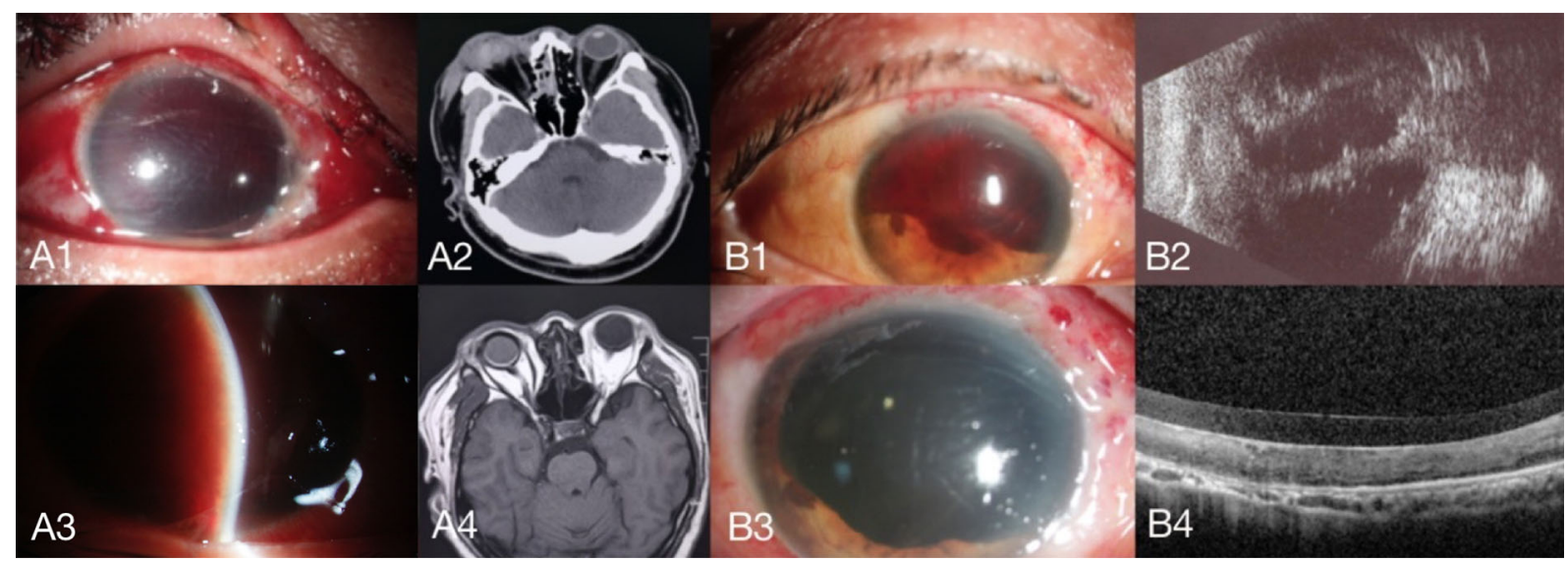

Fig. 4 Anterior segment photos and imaging examination of two patients. A In the air group, a male, 47-year-old patient was diagnosed with severe ocular trauma in the posterior segment of the right eye. A1 Anterior segment image was taken before surgery. A2 Orbital CT before surgery (B-scan check was unsuitable for this patient with an operative history of posterior sclera cracking suturing, and MRI checking was also not recommended because of the presence of intraocular metal foreign body). A3 Corneal blood staining after surgery. A4 Orbital MRI after

baseline IOP, postoperative IOP dropped by $1.42 \pm 2.19 \mathrm{mmHg}$ in the viscoelastic group $(P=0.0231)$ and $1.88 \pm 2.17 \mathrm{mmHg}$ in the air group $(P=0.0051)$ at the 24 th weeks (Table 4$)$.

Three among 27 eyes (11.1\%) showed postvitrectomy hypotony (Fig. 3). The difference between IOP values at the baseline and the last follow-up was more than $5 \mathrm{mmHg}$ in these 3 eyes. Two of these 3 eyes were from the air group; their IOP changed from $14.8 \mathrm{mmHg}$ and $15.7 \mathrm{mmHg}$ at the baseline to $9.3 \mathrm{mmHg}$ and $10.5 \mathrm{mmHg}$ at the last follow-up. In addition, 1 eye was from the viscoelastic group, and the IOP in this eye decreased from 17.1 to $11.8 \mathrm{mmHg}$.

In the air group, corneal blood staining in the anterior chamber was found in 1 eye (Fig. 4), and postoperative diffuse hemorrhage in the anterior chamber and the vitreous cavity was found in 5 eyes among 13 eyes. In contrast, in the viscoelastic group, there was no corneal blood staining among 14 eyes, and transient postoperative diffuse hemorrhage was observed in vitreous cavity of 1 eye (Fig. 3). The duration surgery, the retina was supported by FCVB. B In the viscoelastic group, a male, 43-year-old patient was diagnosed with severe ocular trauma in the posterior segment of the right eye. B1 Anterior segment image was taken before surgery. B2 B-scan ultrasonography before surgery. B3 Anterior segment image after surgery. B4 OCT after surgery, the retina was supported by the 60 - $\mu \mathrm{m}$-thick capsular membrane of FCVB

of diffuse hemorrhage in the vitreous cavity was brief and lasted approximately 1 week.

After FCVB implantation, inflammatory responses, including inflammatory cells, flare, and fibrin, were found in the anterior chamber. Anterior chamber inflammation was observed in $4(28.6 \%)$ eyes from the viscoelastic group and $9(69.2 \%)$ eyes from the air group on the 1 st postoperative day. Among these 9 eyes with anterior chamber inflammation, fibrin exudation in the anterior chamber was observed in 4 eyes in the air group. However, in the viscoelastic group, fibrin exudation in the anterior chamber was only observed in 1 eye (Fig. 3 ). The inflammatory response was most severe on the 1st postoperative day; after that, it gradually declined and lasted until the postoperative 7 th day.

\section{DISCUSSION}

The major findings of this study are (i) injection of Na-HA into the anterior chamber after FCVB implantation could maintain postoperative 
IOP; (ii) no corneal blood staining and diffuse hemorrhage were observed in the anterior chamber; and (iii) postoperative inflammatory response was reduced in the anterior chamber of eyes injected with Na-HA. To the best of our knowledge, this is the first study that evaluated the efficacy of viscoelastic substances applied in the anterior chamber after FCVB implantation. Our results indicated that compared with the use of air in the anterior chamber, Na-HA applied after FCVB implantation could maintain stable postoperative IOP and reduce postoperative complications.

There were no significant differences between the two groups in the reattachment rates of severe retinal detachments in this study. Among 27 eyes, 23 (85.2\%) eyes ultimately attained and sustained anatomic retinal attachment at the last examination (about 6 months). In Lin et al.'s study, retinal reattachments were analyzed by B-scan in $8(72.3 \%)$ out of the 11 eyes at the end of the 3-month treatment time, which was similar to the rates we encountered during our clinical trial [6].

IOP is one of the essential factors in sustaining the shape of an eye. Previous studies have shown that post-vitrectomy hypotony is a well-recognized postoperative complication in the eyes after severe PVR and severe ocular trauma surgery $[14,15]$. In our study, the IOP values on the first to third postoperative days were 8.84-11.15 $\mathrm{mmHg}$ (lower than preoperative values) in the air group and 13.42$14.16 \mathrm{mmHg}$ (closer to baseline IOP values) in the viscoelastic group. Hypotony may occur as a result of increased absorption of intraocular fluid through the area of bare retinal pigment epithelium. Scar tissue can cause dysfunction of the ciliary epithelium and/or mechanical detachment of the ciliary body (CB) $[16,17]$. Yet, the mechanisms through which FCVB implantation produced transient hypotony are not fully understood. There are some possible explanations for transient hypotony after FCVB implantation. First, the inflammatory response of $\mathrm{CB}$ after surgery, resulting from the surgical scleral incision and ciliary body local injury, could contribute to hypotony [18]. It is believed that hypotony in inflammation occurs through a prostaglandin-mediated decrease in aqueous production (aqueous shutdown) combined with an increase in uveoscleral outflow [19]. Second, reoperations are more susceptible to transient hypotony, since significantly more fluid leakage occurs in reoperations than in primary operations [20]. In our study, this was not the primary PPV operation for 11 (40.7\%) patients in both groups. It is possible that previous surgery altered the elasticity and regenerative capacity of scleral tissue, thus rendering wounds in this tissue more prone to leakage. Furthermore, vitrectomized eyes will have a complete excision of the vitreous, resulting in less internal vitreous plugging of sclerotomies [21]. Third, the length of the procedure could influence postoperative inflammation and IOP [22, 23]. In our study, the length of the procedure was $106.8 \pm 8.5 \mathrm{~min}$ in the air group and $110.5 \pm 9.6 \mathrm{~min}$ in the viscoelastic group. FCVB implantation is an unconventional and complicated operation that might involve other concurrent procedures such as $360^{\circ}$ retinotomy, anterior flap retinectomy, radial retinotomy, membrane removal, endo-laser photocoagulation, and cataract surgery. Postoperative intraocular inflammation resulting from the long procedure may promote the development of transient hypotony.

Postoperative chronic hypotony can be defined as the last follow-up IOP of $5 \mathrm{mmHg}$ or even lower compared to the preoperative value. Some previous studies have reported that the percentage of eyes with hypotony after vitrectomy ranges from $6.7 \%$ to $31 \%[24,25]$. In our study, 3 out of 27 eyes (11.1\%) showed postvitrectomy hypotony, which was consistent with previously reported studies. Even though it reached comparable levels, IOP at the 6-month post-implantation time was still lower than the baseline in both groups. The chronic hypotony could be explained by the following: (1) chronic traction of the anterior vitreous base, resulting in shallow detachment of $\mathrm{CB}$, hyposecretion, and subsequent hypotony [25]; (2) mechanical damage of repeated surgery to the ciliary processes; (3) those who underwent $360^{\circ}$ retinectomy. Alturki et al. recorded hypotony in $40 \%$ of a series of eyes in which a $360^{\circ}$ retinectomy was performed [26]. Although the primary aim of retinectomy is to maintain adequate relief of 
traction and successful retinal reattachment, limiting the retinectomy size to the minimum necessary to relieve traction on the retina may also help avoid hypotony.

In the present study, the difference between preoperative and postoperative IOP in the viscoelastic group was significantly smaller than that in the air group from 1st to 3rd day after surgery. The use of Na-HA in the anterior chamber led to temporarily inadequate production of aqueous fluid to some extent, which improved transient hypotony after FCVB implantation. At the same time, the use of NaHA interfered with trabecular network channels for aqueous humor outflow, which maintained stable postoperative IOP. Na-HA does not stay in the anterior chamber for a long time because of its relatively rapid elimination from the eyes. $\mathrm{Na}-\mathrm{HA}$ in the anterior chamber is degraded by the intraocular enzyme hyaluronidase and eliminated through Schlemm's canal and uveoscleral pathways. As a result, there was no difference in postoperative IOP between groups from the 1st week after surgery onwards.

Lin et al. reported that anterior chamber hemorrhaging after FCVB implantation was observed in 3 out of 11 eyes (27.3\%), which was similar to 6 out of 27 eyes (22.2\%) in this study [6]. A large implantation incision of FCVB, about $3.5 \mathrm{~mm}$, could be one of the factors causing postoperative anterior chamber hemorrhage and diffuse hemorrhage in the vitreous cavity. Accordingly, second-generation FCVB should be designed smaller to adapt to a small incision. In our study, corneal blood staining and transient postoperative diffuse hemorrhage were found more often in the eyes of the air group compared to the viscoelastic group. This was likely related to postoperative hypotony in the air group. Viscoelastic agents are used in ophthalmology to protect tissue and cells from mechanical trauma and prevent the influx of blood or efflux of fluid/viscoelastic from the anterior chamber.

Inflammatory cells, flare, or fibrin, the obvious characteristics of an inflammatory response, were found in the anterior chamber after FCVB implantation. In our study, fibrin exudation was found in the anterior chamber of 5 eyes, which accounted for $18.5 \%$, and was higher than the incidence of fibrin exudation (15.3\% and $16.2 \%$ after phacovitrectomy surgery) reported by some researchers $[27,28]$. Surgical trauma is a known cause of inflammation [18]. In this study, a large incision was required for FCVB implantation. FCVB implantation is a complicated operation, which combines multiple operative methods and may promote postoperative inflammation. In the present study, postoperative fibrin exudation was found in 4 out of 13 eyes in the air group compared to 1 out of 14 eyes in the viscoelastic group. Arikan et al. reported that the anterior chamber reaction might significantly increase 1 day after operation [29]. Some studies have reported that the viscoelastic $1 \%$ solution of sodium hyaluronate injected into the eye of an owl monkey can be eliminated from the anterior chamber within 48-72 h [30]. In this study, Na-HA may prevent inflammatory factors in a posterior segment from entering the anterior chamber and then inhibit fibrin exudation in the anterior chamber during the inflammatory response prone stage.

Experimental and clinical studies have demonstrated corneal endothelial damage after exposure to air. This occurs because the air bubble separates the corneal endothelial layer and the aqueous humor, preventing the exchange of nutrients, or the pressure from the air bubble on the cells or trauma, drying out the exposed surface of the endothelial cells. In our study, Na-HA was injected into the anterior chamber that formed a protective viscoelastic layer coating of the corneal endothelium. However, corneal epithelial edema and bandshaped degeneration of cornea postoperative complications were not observed in the air group, which implied that corneal endothelium cell damage was not serious. We speculated that in the air group, as a result of the FCVB implantation into the vitreous cavity, there was a small amount of air in the anterior chamber, which was soon replaced by the aqueous humor.

This study has a few limitations. First, the sample size was relatively small. Patient enrollment was difficult because of fewer patients receiving FCVB implantation and strict inclusion. However, the sample size in this study has 
been scientifically calculated, which could provide $80 \%$ power at a two-sided alpha level of 0.05 and is the largest one among all studies reported on FCVB implantation operation. In addition, other kinds of viscoelastic substances, such as chondroitin sulfate and hydroxypropyl methylcellulose, should also be tested during FCVB operation.

\section{CONCLUSIONS}

Injection of $\mathrm{Na}-\mathrm{HA}$ in the anterior chamber after the FCVB implant was associated with less fluctuation in postoperative IOP and could reduce postoperative complications. Clinical ophthalmologists should consider regularly applying viscoelastic substances like NA-HA for FCVB implantation.

\section{ACKNOWLEDGEMENTS}

The author would like to thank all the participants and the staff for their valuable contribution to this research.

Funding. This study was supported by the Doctoral Research Fund of the Second Affiliated Hospital of Harbin Medical University (No. BS2012-15) and the Natural Science Foundation of Heilongjiang Province, China grant (No. H2017010). The editorial assistance fee was funded by the Chunhui plan of the Heilongjiang Ministry of Education (No. HLJ2019025). The journal's Rapid Servise Fee was funded by the authors.

Editorial Assistance. A professional English proofreading company (MedSci) revised this manuscript.

Authorship. All named authors meet the International Committee of Medical Journal Editors (ICMJE) criteria for this article, take responsibility for the integrity of the work as a whole, and have given their approval for this version to be published.
Authorship Contributions. ZZ designed the study, collected and analyzed the data, and wrote the manuscript; SD designed the study, analyzed the data, and wrote the manuscript; all other authors contributed equally in reviewing, amending, and correcting the manuscript.

Disclosures. The authors, Zhang Zhongyu, Liu Shujie, Xie Fang, Jiang Bo, Sun Meng, and Sun Dawei, have nothing to disclose.

Compliance with Ethics Guidelines. The study was approved by the institutional review board (IRB), the Human Research Ethics Committee of the Second Affiliated Hospital of Harbin Medical University (Registration number ChiCTR-TNC-00000396). It fully complied with the ethical standard of the hospital and following the Helsinki Declaration of 1964 and its later amendments. Written informed consent was obtained from each patient before enrollment in the trial.

Data Availability. The data generated during and/or analyzed during the current study are available from the corresponding author on reasonable request.

Open Access. This article is licensed under a Creative Commons Attribution-NonCommercial 4.0 International License, which permits any non-commercial use, sharing, adaptation, distribution and reproduction in any medium or format, as long as you give appropriate credit to the original author(s) and the source, provide a link to the Creative Commons licence, and indicate if changes were made. The images or other third party material in this article are included in the article's Creative Commons licence, unless indicated otherwise in a credit line to the material. If material is not included in the article's Creative Commons licence and your intended use is not permitted by statutory regulation or exceeds the permitted use, you will need to obtain permission directly from the copyright holder. To view a copy of this licence, visit http://creativecommons.org/licenses/bync/4.0/. 


\section{REFERENCES}

1. Ankamah E, Sebag J, Ng E, Nolan JM. Vitreous antioxidants, degeneration, and vitreoretinopathy: exploring the links. Antioxidants (Basel). 2019;9: 1-20.

2. Alovisi C, Panico C, de Sanctis U, Eandi CM. Vitreous substitutes: old and new materials in vitreoretinal surgery. J Ophthalmol. 2017;6:1-5.

3. Gao Q, Mou S, Ge J, et al. A new strategy to replace the natural vitreous by a novel capsular artificial vitreous body with pressure-control valve. Eye (Lond). 2008;22:461-8.

4. Gao Q, Chen X, Ge J, et al. Refractive shifts in four selected artificial vitreous substitutes based on Gullstrand-Emsley and Liou-Brennan schematic eyes. Invest Ophthalmol Vis Sci. 2009;50:3529-34.

5. Liu Y, Jiang Z, Gao Q, et al. Technical standards of a foldable capsular vitreous body in terms of mechanical, optical, and biocompatible properties. Artif Organs. 2010;34:836-45.

6. Lin X, Ge J, Gao Q, et al. Evaluation of the flexibility, efficacy, and safety of a foldable capsular vitreous body in the treatment of severe retinal detachment. Invest Ophthalmol Vis Sci. 2011;52: 374-81.

7. Zhang R, Wang T, Xie C, et al. Evaluation of supporting role of a foldable capsular vitreous body with magnetic resonance imaging in the treatment of severe retinal detachment in human eyes. Eye (Lond). 2011;25:794-802.

8. Lin X, Wang Z, Jiang Z, et al. Preliminary efficacy and safety of a silicone oil-filled foldable capsular vitreous body in the treatment of severe retinal detachment. Retina. 2012;32:729-41.

9. Landry H, Aminian A, Hoffart L, et al. Corneal endothelial toxicity of air and SF6. Invest Ophthalmol Vis Sci. 2011;52:2279-86.

10. Hesse M, Kuerten D, Walter P, Plange N, Johnen S, Fuest M. The effect of air, SF6 and C3F8 on immortalized human corneal endothelial cells. Acta Ophthalmol. 2017;95:e284-90.

11. Van den Bruel A, Gailly J, Devriese S, Welton NJ, Shortt AJ, Vrijens F. The protective effect of ophthalmic viscoelastic devices on endothelial cell loss during cataract surgery: a meta-analysis using mixed treatment comparisons. Br J Ophthalmol. 2011;95:5-10.

12. Cekic O, Ohji M, Zheng Y, Hayashi A, Kusaka S, Tano Y. Experimental study of viscoelastic in the prevention of corneal endothelial desiccation injury from the vitreal fluid-air exchange. Am J Ophthalmol. 2003;135:641-7.

13. Wysenbeek YS, Loya N, Ben Sira I, Ophir I, Ben SY. The effect of sodium hyaluronate on the corneal epithelium. An ultrastructural study. Invest Ophthalmol Vis Sci. 1988;29:194-9.

14. Tsui I, Schubert HD. Retinotomy and silicone oil for detachments complicated by anterior inferior proliferative vitreoretinopathy. $\mathrm{Br} \mathrm{J}$ Ophthalmol. 2009;93:1228-33.

15. Tseng JJ, Schiff MW, Barile GR, et al. Influence of postoperative lens status on intraocular pressure in proliferative vitreoretinopathy. Am J Ophthalmol. 2009;147:875-85.

16. Kolomeyer AM, Grigorian RA, Mostafavi D, Bhagat $\mathrm{N}$, Zarbin MA. 360 retinectomy for the treatment of complex retinal detachment. Retina. 2011;31: 266-74.

17. Tseng JJ, Barile GR, Schiff WM, Akar Y, Vidne-Hay $\mathrm{O}$, Chang S. Influence of relaxing retinotomy on surgical outcomes in proliferative vitreoretinopathy. Am J Ophthalmol. 2005;140:628-36.

18. Nishino M, Eguchi H, Iwata A, Shiota H, Tanaka M, Tanaka T. Are topical steroids essential after uneventful cataract surgery? J Med Invest. 2009;56: $11-5$.

19. Bellows A, Chylack L, Hutchinson B. Choroidal detachment, clinical manifestations, therapy and mechanism of formation. Ophthalmology. 1981;88:1107-15.

20. Shimada H, Nakashizuka H, Mori R, Mizutani Y, Hattori T. 25-gauge scleral tunnel transconjunctival vitrectomy. Am J Ophthalmol. 2006;142:871-3.

21. Bamonte G, Mura M, Stevie TH. Hypotony after 25-gauge vitrectomy. Am J Ophthalmol. 2011;151: 156-60.

22. Mitsui K, Kogo J, Takeda H, et al. Comparative study of 27 gauge versus 25-gauge vitrectomy for epiretinal membrane. Eye. 2016;30:538-44.

23. Lubinski W, Gosławski W, Podboraczynska-Jodko K, Mularczyk M, Post M. Comparison of 27-gauge versus 25-gauge vitrectomy results in patients with epiretinal membrane: 6-month follow-up. Int Ophthalmol. 2020;40:867-85.

24. Lim AK, Alexander SM, Lim KS. Combined larger radial-retinotomy and circumferential retinectomy in the management of advanced proliferative vitreoretinopathy. Retina. 2009;29:112-6. 
25. Hocaoglu M, Karacorlu M, Muslubas IS, Ozdemir H, Arf S, Uysal O. Peripheral 360 degree retinotomy, anterior flap retinectomy, and radial retinotomy in the management of complex retinal detachment. Am J Ophthalmol. 2016;163:115-21.

26. Alturki WA, Peyman GA, Paris CL, Blinder KJ, Desai UR, Nelson NC. Posterior relaxing retinotomies: analysis of anatomic and visual results. Ophthalmic Surg. 1992;23:685-8.

27. Treumer F, Bunse A, Rudolf M, Roider J. Pars plana vitrectomy, phacoemulsification, and intraocular lens implantation. Comparison of clinical complications in a combined versus two-step surgical approach. Graefes Arch Clin Exp Ophthalmol. 2006;244:808-15.
28. Smith M, Raman SV, Pappas G, Simcock P, Ling R, Shaw S. Phacovitrectomy for primary retinal detachment repair in presbyopes. Retina. 2007;27: 462-7.

29. Arikan Yorgun M, Toklu Y, Mutlu M, Ozen U. Clinical outcomes of 25-gauge vitrectomy surgery for vitreoretinal diseases: comparison of vitrectomy alone and phaco-vitrectomy. Int J Ophthalmol. 2016;9:1163-9.

30. Schubert HD, Denlinger JL, Balazs EA. Exogenous Na-hyaluronate in the anterior chamber of the owl monkey and its effect on the intraocular pressure. Exp Eye Res. 1984;39:137-52. 